\title{
Complete placenta previa in the second trimester: clinical and sonographic factors associated with its resolution
}

\author{
Xueyin Li ${ }^{1}$, Yun Feng ${ }^{2}$ \\ 'Zhengzhou First People's Hospital, China \\ ${ }^{2}$ The First Affiliated Hospital of Zhengzhou University, China
}

\begin{abstract}
Objectives: This study was carried out to evaluate outcomes of pregnancies with complete placenta previa diagnosed in mid-pregnancy, and evaluate whether a history of caesarean section and placenta location effect the resolution of placenta previa.

Material and methods: A prospective observational study was conducted on patients diagnosed with complete placenta previa by ultrasound examination between $20+0$ weeks and $25+6$ weeks of gestation. Patients were grouped in terms of placenta location (anteriorly or posteriorly located) and presence/absence of prior caesarean section. Maternal demographics, ultrasound findings and pregnancy outcomes were subsequently compared between these groups. Statistical analysis was performed by using SPSS version 16.0.

Results: 70 patients with the above characteristics were recruited in our study. Of the 70 patients, 21 (30\%) had prior caesarean section, and 41 (58.6\%) had an anteriorly located placenta. Patients with prior cesarean delivery delivered earlier $(36.9 \pm 2.2$ weeks versus $38.0 \pm 1.8$ weeks, $\mathrm{P}=0.039)$. Furthermore, $74.3 \%$ of the placenta previa resolved by delivery. Prior caesarean section (RR 2.941, 95\% Cl 0.938-9.216, P 0.024) and anterior placenta (RR 3.805, 95\% Cl 1.126-12.855, P 0.031) were related to greater risk of persistence of placenta previa to term.

Conclusions: Prior caesarean section and anteriorly located placenta are important factors that modify the risk that previa will complicate delivery. Our findings may be useful for patient counselling and future management of the condition.

Key words: placenta previa; cesarean section; prenatal ultrasonography; pregnancy outcome
\end{abstract}

Ginekologia Polska 2019; 90, 9: 539-543

\section{INTRODUCTION}

Peripartum hemorrhage is one of the most preventable causes of maternal mortality worldwide [1]. Complete placenta previa (CPP) is a major contributor to severe postpartum hemorrhage (PPH), especially when it is associated with placenta accreta. CPP is associated with increased maternal perinatal morbidity and mortality [2]. As revealed by ultrasound examination, the incidence of CPP during the second trimester is reportedly between $0.49 \%$ and $5.6 \%[3,4]$. Although more than $90 \%$ of placenta previa discovered at mid-pregnancy resolves prior to delivery, CPP is more likely to persist [5].

Several studies show that CPP might be an entity clinically different from incomplete placenta previa and associated with worse pregnancy outcomes [6-10]. Development of ultrasonic imaging has led to better understanding of the relationship between the internal cervical os and the placental margin and allowed us to more precisely identify the location of the placenta and the type of placenta previa. Nonetheless, data are still limited concerning the pregnancy outcomes of patients with CPP diagnosed at mid-pregnancy.

Furthermore, studies have reported widely different results regarding the resolution of placenta previa [11-13]. Multiple investigators have studied the impact of placenta location and prior caesarean section on the resolution of placenta previa but have reached notably different conclusions $[5,11,14-16]$. It is not known whether these factors exert any effect on the resolution of CPP.

\section{Objectives}

This study was carried out to evaluate the pregnancy outcomes of patients diagnosed with CPP at mid-pregnancy 
to better understand the influence of prior caesarean section and placenta location on the resolution of placenta previa.

\section{MATERIAL AND METHODS}

This prospective cohort study examined patients with singleton pregnancies who underwent ultrasound examination during mid-pregnancy. The study protocol was approved by the local Institutional Review Board, and an informed consent for the research was obtained from all subjects in accordance with the World Medical Association Declaration of Helsinki. Patient anonymity was preserved. This study does not violate the policies and/or procedures described in'Specific Inappropriate Acts in Publication Process. Women were enrolled if they were diagnosed with CPP between $20^{+0}$ weeks and $25^{+6}$ weeks of gestation. To evaluate whether resolution occurred, the women were sonographically examined every 4 to 6 weeks. On each ultrasonic examination, gestational age (GA) at the examination and the distance in centimetres between the placental margin and the internal cervical os were recorded. All participants were followed until they delivered, and data were collected, including intraoperative confirmation of placenta previa. Patients whose pregnancies were terminated because of malformations and who delivered in other hospitals were excluded from the evaluation.

Between April 2014 to January 2015, 70 patients in total were recruited in our study. Patients were grouped in terms of placenta location (anteriorly or posteriorly located) and presence/absence of a history of caesarean section. In this study, CPP was defined when a placenta covered the internal os of the cervix completely, while the position was defined as normal when placental-cervical distance was more than $2 \mathrm{~cm}$. Maternal demographics, ultrasound findings and pregnancy outcomes were then compared between these groups. Postpartum hemorrhage in this study is defined as a blood loss of $1000 \mathrm{~mL}$ or greater, or a blood loss with associated signs or symptoms of hypovolemia, that occurs within $24 \mathrm{~h}$ of delivery, regardless of the mode of delivery.

SPSS version 16.0 (SPSS, Chicago, IL) was adopted to perform statistical analysis. Continuous variables were expressed as the mean \pm standard deviation or medians. Qualitative variables were presented as absolute frequency and percentage. Cox regression analysis was used for statistical analysis. $P$ value $<0.05$ was considered significant.

\section{RESULTS}

70 women were enrolled in this study. 21 women had a prior caesarean delivery, and 49 did not. 41 CPPs were located anteriorly and 29 posteriorly. Patients with prior cesarean delivery tended to be advanced in age $(34.7 \pm 4.8 \mathrm{vs}$ $30.5 \pm 4.0, \mathrm{P}=0.000)$, gravidity $(4.1 \pm 1.6$ vs $2.0 \pm 1.2, \mathrm{P}=0.000)$ and parity $(0.8 \pm 0.6$ vs $0.1 \pm 0.2, P=0.000)$. Incidence of prior dilatation and curettage was also increased in this group. However, there was no significant difference in these maternal characteristics between anterior and posterior groups (Tab. 1).

While mean gestational age at initial diagnosis was similar for cesarean group and non-cesarean group, mean gestational age at resolution was obviously later in cesarean group ( $36.4 \pm 2.7$ vs $30.5 \pm 5.3, P=0.000$ ), indicating that placenta migrated slower in these patients (Tab. 2). Patients with prior cesarean delivery resolved less frequently $(33.3 \%$ vs $91.8 \%$, $P=0.000)$ and delivered earlier (36.9 \pm 2.2 vs $38.0 \pm 1.8$, $P=0.039$ ). Mean $G A$ at initial diagnosis, at resolution and at delivery were the same for anterior group and posterior group. However, resolution of CPP occurred more often in women with posteriorly located placenta $(55.2 \%$ vs $87.8 \%$, $P=0.002$ ).

Table 3 shows odds for the persistence of placenta previa to term. In a Cox regression model, after adjusted for maternal age $\geq 35$ and prior abortion, prior caesarean section (RR 2.941,95\% Cl 0.938-9.216, P 0.024) and anterior placenta

Table 1. Demographic data stratified by prior CS and placenta location

\begin{tabular}{|l|l|l|l|l|l|l|}
\hline & \multicolumn{3}{l|}{ Placenta location } \\
\hline Characteristic & Yes $(\mathbf{n}=\mathbf{2 1})$ & No $(\mathbf{n}=\mathbf{4 9})$ & $\mathbf{P}$ & Anterior $(\mathbf{n}=\mathbf{4 1})$ & Posterior $(\mathbf{n}=\mathbf{2 9})$ & $\mathbf{P}$ \\
\hline Maternal age [years] & $34.7 \pm 4.8$ & $30.5 \pm 4.0$ & 0.000 & $32.7 \pm 4.2$ & $31.1 \pm 4.8$ & 0.159 \\
\hline Gravity & $4.1 \pm 1.6$ & $2.0 \pm 1.2$ & 0.000 & $3.1 \pm 1.9$ & $2.3 \pm 1.2$ & 0.051 \\
\hline Parity & $0.8 \pm 0.6$ & $0.1 \pm 0.2$ & 0.000 & $0.4 \pm 0.6$ & $0.2 \pm 0.5$ & 0.092 \\
\hline Prior dilatation and curettage & $17(81.0 \%)$ & $26(53.1 \%)$ & 0.028 & $20(69.0 \%)$ & $23(56.1 \%)$ & 0.276 \\
\hline Prior uterine surgery & $5(23.8 \%)$ & $8(16.3 \%)$ & 0.687 & $8(27.6 \%)$ & $5(12.2 \%)$ & 0.103 \\
\hline Assisted reproductive technology & $4(19.0 \%)$ & $11(22.4 \%)$ & 1.000 & $7(24.1 \%)$ & $8(19.5 \%)$ & 0.642 \\
\hline Posterior placenta & $10(47.6 \%)$ & $31(63.3 \%)$ & 0.223 & - & - & - \\
\hline Prior cesarean section & - & - & - & $11(37.9 \%)$ & $10(24.4 \%)$ & 0.223 \\
\hline
\end{tabular}

Data are presented as mean \pm SD or number (percent) 
Table 2. Data of placental migration stratified by prior CS and placenta location

\begin{tabular}{|l|l|l|l|l|l|l|}
\hline & \multicolumn{3}{l|}{ Prior cesarean section } & \multicolumn{3}{l|}{ Placenta location } \\
\hline Characteristic & Yes $(\mathbf{n}=\mathbf{2 1})$ & No $(\mathbf{n}=\mathbf{4 9})$ & $\mathbf{P}$ & Anterior $(\mathbf{n}=\mathbf{4 1})$ & Posterior $(\mathbf{n}=\mathbf{2 9})$ & $\mathbf{P}$ \\
\hline Gestational age at initial detection & $23.2 \pm 1.3$ & $22.8 \pm 1.9$ & 0.416 & $23.3 \pm 2.0$ & $22.7 \pm 1.5$ & 0.144 \\
\hline Gestational age at resolution & $36.4 \pm 2.7$ & $30.5 \pm 5.3$ & 0.000 & $31.7 \pm 6.0$ & $30.8 \pm 5.1$ & 0.331 \\
\hline Rate of resolution & $7(33.3 \%)$ & $45(91.8 \%)$ & 0.000 & $36(87.8 \%)$ & $16(55.2 \%)$ & 0.002 \\
\hline Gestational age at delivery [weeks] & $36.9 \pm 2.2$ & $38.0 \pm 1.8$ & 0.039 & $37.3 \pm 2.2$ & $37.9 \pm 1.8$ & 0.615 \\
\hline
\end{tabular}

Data are presented as mean \pm SD or number (percent)

(RR 3.805, 95\% Cl 1.126-12.855, P 0.031) were significantly related to greater risk of persistence of placenta previa to term. 52 (74.3\%) CCPs eventually resolved. The mean GA at resolution was $31.2 \pm 3.4$ weeks (Tab. 4 and 5). Overall, $10 \%$ of placenta previa resolved before 28 weeks of gestation, $31.4 \%$ before 32 weeks and $62.9 \%$ before 36 weeks, while a small number [8 (11.4\%)] resolved at or after 36 weeks.

Data for 18 patients whose placenta previa did not resolve by delivery are summarized in Table 6 . These patients consisted of 12 patients with CPP; 1 with partial placenta previa, 3 with marginal placenta previa and 1 with a low-lying placenta at last ultrasound examination or at delivery. All 18 patients had caesarean deliveries. 3 patients were delivered emergently and 3 suffered from postpartum haemorrhage.

Our results showed no significant difference in obstetric outcomes and neonatal outcomes between cesarean group and non-cesarean group, and between anterior group and posterior group (Data was not shown). No subjects received hysterectomy in this series.

\section{DISCUSSION}

This study evaluated the outcomes of CPP discovered in mid-pregnancy and the impact of prior caesarean section and placental location on the resolution of CPP.

The significant decrease in maternal perinatal mortality has been ascribed to two major progress in the management of placenta previa: the liberal use of cesarean section plus maternal blood transfusion supply and expectant treatment of placenta previa. Nevertheless, placenta previa still contributes to a prominent proportion of maternal perinatal morbidity and mortality. However, no serious complications, such as hysterectomy or foetal death, occurred in our study.

The resolution rate of CPP before delivery in our study was $74.3 \%$ with a mean GA of $31.2 \pm 3.4$ weeks at clearance. Overall, $10 \%$ of placenta previa resolved before 28 weeks of gestation, $31.4 \%$ before 32 weeks and $62.9 \%$ before 36 weeks. To date, reports on the resolution of CPP diagnosed in mid-pregnancy are scanty, and their findings are inconsistent. A study conducted by Townsend in 1986 suggested that the placenta did not migrate in cases of central previa

\begin{tabular}{l|l|l|l|}
\multicolumn{4}{|l}{ Table 3. Odds for the persistence of placenta previa } \\
\hline Characteristic & RR & $\mathbf{9 5 \%}$ Cl & P \\
\hline Maternal age $\geq 35$ years & 1.276 & $0.454-3.588$ & 0.664 \\
\hline Prior abortion & 3.127 & $0.760-12.873$ & 0.114 \\
\hline Prior cesarean section & 2.941 & $0.938-9.216$ & 0.024 \\
\hline Anterior placenta & 3.805 & $1.126-12.855$ & 0.031 \\
\hline
\end{tabular}

Table 4. Clearance of placenta based on $\mathrm{GA}$ at initial diagnosis of a CPP

\begin{tabular}{|l|l|l|l|l|l|}
\hline $\begin{array}{l}\text { GA at diagnosis } \\
\text { [weeks] }\end{array}$ & \multicolumn{2}{|l|}{ Patients } & \multicolumn{2}{l|}{ Cleared } & \multicolumn{2}{l}{ Mean GA at } \\
clearance [weeks]
\end{tabular}

$\mathrm{GA}$ - gestational age

Table 5. Patients whose placentas cleared by a specific GA range

\begin{tabular}{|c|c|c|c|}
\hline \multirow{2}{*}{$\begin{array}{l}\text { GA at clearance } \\
\text { [weeks] }\end{array}$} & \multicolumn{2}{|c|}{ Cleared } & \multirow{2}{*}{$\begin{array}{l}\text { Cumulative } \\
\text { clearance, } \%\end{array}$} \\
\hline & $n$ & $\%$ & \\
\hline $24.0-27.6$ & 7 & 10.00 & 10.00 \\
\hline $28.0-31.6$ & 15 & 21.43 & 31.43 \\
\hline $32.0-35.6$ & 22 & 31.43 & 62.86 \\
\hline 36.0-delivery & 8 & 11.40 & 74.26 \\
\hline
\end{tabular}

GA - gestational age

discovered between 14 and 26 weeks of gestation [17]. Over the past 30 years, ultrasonographic examination in the diagnosis of placenta previa has greatly advanced; therefore, the study may not be relevant. Another study in 2000 found that the entire placenta previa did not migrate during the third trimester[12]. However, the power of their study may be limited due to a small sample size of CPP subjects. Recently, Blouin et al. [18] carried out a retrospective cohort study on 714 cases of complete or incomplete previa. Coincidently with our findings, their study showed that $12 \%$ of CCP discovered between 15 and 19 weeks of 
Table 6. Summary of 18 patients whose placenta previa persist to delivery

\begin{tabular}{|c|c|c|c|c|c|c|c|c|}
\hline $\begin{array}{l}\text { GA at diagnosis } \\
\text { [weeks] }\end{array}$ & Age [years] & Prior CS & $\begin{array}{l}\text { Placental } \\
\text { location }\end{array}$ & $\begin{array}{l}\text { GA at delivery } \\
\text { [weeks] }\end{array}$ & Previa type & Emergency CS & PPH & Hysterectomy \\
\hline 22.0 & 31 & No & Anterior & 36.5 & Complete & No & No & No \\
\hline 22.6 & 34 & Yes & Anterior & 38.3 & Complete & No & No & No \\
\hline 22.3 & 29 & No & Anterior & 38.6 & Complete & No & No & No \\
\hline 22.3 & 40 & Yes & Posterior & 39.5 & Marginal & No & No & No \\
\hline 23.1 & 32 & No & Anterior & 38.6 & Complete & Yes & No & No \\
\hline 22.0 & 38 & Yes & Posterior & 38.6 & Marginal & No & No & No \\
\hline 22.5 & 35 & Yes & Anterior & 37.3 & Complete & No & Yes & No \\
\hline 24.1 & 37 & Yes & Anterior & 39 & Partial & No & No & No \\
\hline 23.3 & 32 & Yes & Anterior & 39.6 & Complete & No & No & No \\
\hline 23.1 & 24 & Yes & Posterior & 38.2 & Complete & No & No & No \\
\hline 23.3 & 36 & Yes & Anterior & 38 & Marginal & Yes & No & No \\
\hline 25.1 & 30 & Yes & Posterior & 39 & Complete & No & No & No \\
\hline 23.0 & 33 & Yes & Posterior & 37.4 & Complete & No & No & No \\
\hline 22.3 & 32 & Yes & Anterior & 36.1 & Complete & No & No & No \\
\hline 21.0 & 40 & Yes & Anterior & 40.2 & Low-lying & Yes & No & No \\
\hline 25.2 & 41 & Yes & Anterior & 37.1 & Complete & No & Yes & No \\
\hline 23.3 & 36 & Yes & Anterior & 37.1 & Complete & No & No & No \\
\hline 21.1 & 31 & No & Anterior & 40 & Complete & No & Yes & No \\
\hline
\end{tabular}

$\mathrm{GA}$ - gestational age; $\mathrm{CS}$ - cesarean section; $\mathrm{PPH}$ - postpartum hemorrhage

gestation and $34 \%$ of those discovered between 20 and 23 weeks of gestation persisted to delivery. Similarly, Lal et al. and Osmundson et al. showed that the resolution rates in CPP diagnosed during the second trimester were $84 \%$ and $59.1 \%$, respectively $[13,19]$.

While it is well-documented that placental migration occurs during the second half of pregnancy in most mid-pregnancy placenta previas, the exact mechanism has not been thoroughly elucidated to date. One of the explanations is that thin placental margins gradually atrophy due to poor vascularization, meanwhile other regions continue to develop, and consequently, migrate towards better vascularized regions. However, it seems that the placental migration rate is not constant. Some factors, such as type of placenta previa, placental location, prior caesarean section, degree of coverage over internal cervical os, gestational week and distance of placental edge from the internal os at initial detection, were reportedly associated with placental migration $[4,5,14,19-23]$.

The influence of prior caesarean delivery on placental migration has been previously reported. Recently, Naji et al. [14] demonstrated that the presence of a caesarean section scar influenced the site of placental implantation but exerted no effect on placental migration in future pregnancies. Inconsistent with that finding, other studies showed that prior caesarean section related to a smaller chance of resolution.
The scarred lower uterine segment caused by prior surgery was believed to impede placental migration, resulting in less frequent resolution [11]. Furthermore, caesarean section served as the primary contributor to placenta accreta or increta [24], which may impede placental migration. Consistent with these findings, our study showed that prior caesarean section significantly decreased the likelihood of resolution of placenta previa by delivery.

In studies by Lal et al. [11] and Eichelberger et al. [19], migration rates in anteriorly situated placentae showed no difference from that of posteriorly situated ones. However, Magann et al. [16] showed a higher possibility of resolution in posteriorly located previa, and attributed the phenomenon to the disproportion in the growth of uterine smooth muscles between anterior placentas and posterior ones. Conversely, other studies believed that placenta previa with an anteriorly located placenta was more likely to migrate, and the migration was secondary to a thinner lower uterine segment on the anterior portion of the uterus, leading to a more pronounced upward migration [11, 25]. While Lal et al. [11] demonstrated that placental location did not influence the resolution of placenta previa. we found that resolution was more frequent in women with posteriorly located CPP. Since the two studies were of prospective design, and had a similar number of subjects, the difference might be ascribed to the racial difference. 
The power of the study lay in its prospective nature. The main limitations included: the relatively small size of the subject population and that it was only a single-center study. A larger and multi-center study is warranted to further confirm the findings in this study.

\section{CONCLUSIONS}

In summary, when a complete placenta previa is diagnosed mid-pregnancy, a small percentage of the cases will persist to delivery. What is more, prior caesarean section and anteriorly located placenta are important factors that modify the risk that previa will complicate delivery. Such information may be useful for counseling patients and assisting with future management decisions.

\section{Acknowledgements}

I would like to thank the staff of the Ultrasound Department of Obstetrics Gynaecology for patients enrolment. I would also like to extend my special gratitude to the staff of the Medical Records Department for data collection.

\section{REFERENCES}

1. Kollmann M, Gaulhofer J, Lang U, et al. Placenta praevia: incidence, risk factors and outcome. J Matern Fetal Neonatal Med. 2016; 29(9): 1395-1398, doi: 10.3109/14767058.2015.1049152, indexed in Pubmed: 26043298.

2. Tuzovic L. Complete versus incomplete placenta previa and obstetric outcome. Int J Gynaecol Obstet. 2006; 93(2): 110-117, doi: 10.1016/j. ijgo.2006.02.006, indexed in Pubmed: 16563394.

3. Wexler P, Gottesfeld KR, Wexler P, et al. Second trimester placenta previa. An apparently normal placentation. Obstet Gynecol. 1979; 54(2): 231-234.

4. Becker $\mathrm{RH}$, Vonk $\mathrm{R}$, Mende $\mathrm{BC}$, et al. The relevance of placental location at 20-23 gestational weeks for prediction of placenta previa at delivery: evaluation of 8650 cases. Ultrasound Obstet Gynecol. 2001; 17(6): 496-501, doi: 10.1046/j.1469-0705.2001.00423.x, indexed in Pubmed: 11422970.

5. Dashe JS, McIntire DD, Ramus RM, et al. Persistence of placenta previa according to gestational age at ultrasound detection. Obstet Gynecol. 2002; 99(5 Pt 1):692-697, doi: 10.1016/s0029-7844(02)01935-x, indexed in Pubmed: 11978274.

6. Dola $\mathrm{CP}$, Garite $\mathrm{TJ}$, Dowling $\mathrm{DD}$, et al. Placenta previa: does its type affect pregnancy outcome? Am J Perinatol. 2003; 20(7): 353-360, doi: 10.1055/s-2003-45282, indexed in Pubmed: 14655091.

7. Gorodeski IG, Bahari CM. The effect of placenta previa localization upon maternal and fetal-neonatal outcome. J Perinat Med. 1987; 15(2): 169-177, indexed in Pubmed: 3656049.

8. Morgan J. Placenta praevia: report on a series of 538 cases (1938-1962). J Obstet Gynaecol Br Commonw. 1965; 72(5): 700-705, indexed in Pubmed: 5843724.

9. Crenshaw C, Jones DE, Parker RT. Placenta previa: a survey of twenty years experience with improved perinatal survival by expectant therapy and cesarean delivery. Obstet Gynecol Surv. 1973; 28(7): 461-470, indexed in Pubmed: 4548519.

10. Cotton DB, Read JA, Paul RH, et al. The conservative aggressive management of placenta previa. Am J Obstet Gynecol. 1980; 137(6): 687-695, doi: 10.1016/s0002-9378(15)33242-7, indexed in Pubmed: 7395932.

11. Lal AK, Nyholm J, Wax J, et al. Resolution of complete placenta previa: does prior cesarean delivery matter? J Ultrasound Med. 2012; 31(4): $577-$ 580, doi: 10.7863/jum.2012.31.4.577, indexed in Pubmed: 22441914.

12. Ghourab S, Al-Jabari A. Placental migration and mode of delivery in placenta previa: transvaginal sonographic assessment during the third trimester. Ann Saudi Med. 2000; 20(5-6): 382-385, doi: 10.5144/02564947.2000.382, indexed in Pubmed: 17264627.

13. Osmundson SS, Wong $A E$, Gerber SE. Second-trimester placental location and postpartum hemorrhage. J Ultrasound Med. 2013; 32(4): 631-636, doi: 10.7863/jum.2013.32.4.631, indexed in Pubmed: 23525388.

14. Naji O, Daemen A, Smith A, et al. Does the presence of a cesarean section scar influence the site of placental implantation and subsequent migration in future pregnancies: a prospective case-control study. Ultrasound Obstet Gynecol. 2012; 40(5): 557-561, doi: 10.1002/uog.11133, indexed in Pubmed: 22323094

15. Kurjak A, Barsić B. Changes of placental site diagnosed by repeated ultrasonic examination. Acta Obstet Gynecol Scand. 1977; 56(3): 161-165, doi: 10.3109/00016347709162113, indexed in Pubmed: 878857.

16. Magann EF, Evans SF, Newnham JP. Placental implantation at 18 weeks and migration throughout pregnancy. South Med J. 1998; 91(11): 1025-1027, doi: 10.1097/00007611-199811000-00006, indexed in Pubmed: 9824183.

17. Townsend RR, Laing FC, Nyberg DA, et al. Technical factors responsible for "placental migration": sonographic assessment. Radiology. 1986; 160(1): 105-108, doi: 10.1148/radiology.160.1.3520642, indexed in Pubmed: 3520642.

18. Blouin D, Rioux C. Routine third trimester control ultrasound examination for low-lying or marginal placentas diagnosed at mid-pregnancy: is this indicated? J Obstet Gynaecol Can. 2012; 34(5): 425-428, doi: 10.1016/S1701-2163(16)35238-0, indexed in Pubmed: 22555134.

19. Eichelberger KY, Haeri S, Kessler DC, et al. Placenta previa in the second trimester: sonographic and clinical factors associated with its resolution. Am J Perinatol. 2011; 28(9): 735-739, doi: 10.1055/s-0031-1280853, indexed in Pubmed: 21660901.

20. Heller HT, Mullen KM, Gordon RW, et al. Outcomes of pregnancies with a low-lying placenta diagnosed on second-trimester sonography. J Ultrasound Med. 2014; 33(4): 691-696, doi: 10.7863/ultra.33.4.691, indexed in Pubmed: 24658950.

21. Oppenheimer L, Holmes P, Simpson N, et al. Diagnosis of low-lying placenta: can migration in the third trimester predict outcome? Ultrasound Obstet Gynecol. 2001; 18(2): 100-102, doi: 10.1046/j.1469-0705.2001.0 0450.x, indexed in Pubmed: 11529986.

22. Lauria MR, Smith RS, Treadwell MC, et al. The use of second-trimester transvaginal sonography to predict placenta previa. Ultrasound Obstet Gynecol. 1996; 8(5): 337-340, doi: 10.1046/j.1469-0705.1996.08050337 $x$, indexed in Pubmed: 8978009.

23. VarmaTR. The implication of a low implantation of the placenta detected by ultrasonography in early pregnancy. Acta Obstet Gynecol Scand. 1981; 60(3): 265-268, doi: 10.3109/00016348109158129, indexed in Pubmed: 7270095.

24. Palacios-Jaraquemada JM. Caesarean section in cases of placenta praevia and accreta. Best Pract Res Clin Obstet Gynaecol. 2013; 27(2): 221-232, doi: 10.1016/j.bpobgyn.2012.10.003, indexed in Pubmed: 23127895.

25. Cho JY, Lee $\mathrm{YH}$, Moon $\mathrm{MH}$, et al. Difference in migration of placenta according to the location and type of placenta previa. J Clin Ultrasound. 2008; 36(2): 79-84, doi: 10.1002/jcu.20427, indexed in Pubmed: 18067142. 